\title{
Metonymic Euphemisms from a Cognitive Linguistic Point of View
}

\author{
Alexander Tokar
}

\begin{abstract}
This article presents a classification of metonymy-based euphemism-formation mechanisms from a cognitive linguistic point of view. It is argued that all metonymic euphemisms can be analyzed as products of three major euphemismformation strategies: 1) violation of the principle IMPORTANT OVER LESS IMPORTANT; 2) violation of the principle SPECIFIC OVER GENERIC; and 3) violation of the principle MORE TRUE OVER LESS TRUE.
\end{abstract}

\section{Introduction}

It is a well-known fact that taboo-marked concepts are often expressed by metonymic euphemisms, i. e., expressions like to sleep with somebody and boyfriend, whose euphemistic senses "to copulate with somebody" / "a regular male sexual partner of almost any age over puberty in a non-marital sexual relationship" are contiguously related to their literal senses "to be in the state of sleep" / "a friend who is a boy." Thus, a person with whom a woman has a regular nonmarital sexual relationship is often perceived as her friend in the literal meaning of this word, i.e., as any person whom she "know[s] well and regard[s] with affection and trust" (WordNet). Additionally, copulation is often followed by physical sleeping, i. e., lovers have sex and then fall asleep together in the same bed.

However, despite the recognition of the role of metonymy as an important euphemism-formation mechanism (e. g., Blank, 1999), there have been almost no studies on the typology of metonymic euphemisms, i. e., studies dealing with the 
question of whether metonymy-based euphemisms prefer a particular semantic pattern (e.g., part-for-whole metonymy) and, if so, why this is the case. Drawing upon the seminal work on metonymy by Kövecses \& Radden (1998), this article attempts to fill in the research gap by classifying metonymic euphemisms into the following three categories: 1) metonymic euphemisms whose vehicle concepts violate the principle IMPORTANT OVER LESS IMPORTANT; 2) metonymic euphemisms whose vehicle concepts violate the principle SPECIFIC OVER GENERIC; and 3) metonymic euphemisms whose vehicle concepts violate the principle MORE TRUE OVER LESS TRUE.

The article utilizes the following structure. The next section discusses the defining characteristics of euphemistic expressions. That is, for example, how do we know that the aforementioned to sleep with somebody and boyfriend are indeed euphemisms? The following section provides a general classification of euphemismformation mechanisms into semantic and non-semantic types: Among other things, it will be argued that all semantically motivated euphemisms can be analyzed as products of either metonymic or metaphoric semantic change. The final sections present a critical discussion of the distinction between default and nondefault metonymies proposed by Kövecses \& Radden (1998) and elaborate on the classification of metonymic euphemisms into the three categories named above.

\section{Euphemism and related phenomena}

A euphemism can be defined as an indirect means of expressing a taboo-marked (i. e., a distasteful, unpleasant) concept. ${ }^{1}$ For example, the euphemistic phrase to sleep with somebody expresses the taboo-marked meaning "to copulate with somebody" without explicitly referring to the taboo subject sEx: To sleep with somebody literally means "to spend time together while being in the state of sleep," not "to have sex." Similarly, the compound boyfriend expresses the taboo-marked meaning "a regular male sexual partner in a non-marital sexual relationship"

1 In this respect, a euphemism may not differ from a dysphemism. For example, just like the euphemism to sleep with somebody, the dysphemism to bang somebody can also be seen as an indirect means of expressing the taboo-marked meaning "to have sex with somebody": To bang does not literally mean "to copulate" but "to strike sharply" (Merriam-Webster Online). The difference between the two expressions is that the euphemism to sleep with somebody is a much more polite means of expressing the meaning "to have sex" than the dysphemism to bang somebody: According to Merriam-Webster Online, the latter is a vulgar expression. 
without explicitly referring to the fact that a boyfriend is a sexual partner: If we consider only the literal meanings of the components boy and friend, we arrive at the taboo-free meaning "a friend who is a boy," not "a sexual partner."

According to Holder (2008:vii), "In speech or writing we use euphemism for dealing with taboo or sensitive subjects. It is therefore the language of evasion, hypocrisy, prudery, and deceit." A more recent study (Moskvin, 2010:75-99), however, insists on the separation of euphemism from related phenomena, such as, for example, lie. To illustrate this point, let us consider the following utterance: Daddy's in Heaven to explain that "Daddy is dead." Like sexuality, death is (in many cultures) a taboo-marked topic, which has given rise to numerous euphemistic expressions. Already in 1936, Louise Pound published an article entitled "American Euphemisms for Dying, Death, and Burial: An Anthology" (1936), in which she mentioned such death-related phrases and utterances as he has left us, gone from us, sunk into his last sleep, called to the eternal sleep, laid to rest, rests in peace till we meet again, gone to his Heavenly Father, gone to meet his Savior, answered the final call, played his last card, etc.

What is particularly interesting about these expressions is that most of them can be used as both euphemisms and non-euphemisms. With regard to the latter, consider the following situation: The speaker of Daddy's in Heaven is a religious person who firmly believes in the afterlife. Evidently, the utterance Daddy's in Heaven is, for that speaker, in no respect different from an utterance like Daddy's in Berlin now (uttered when the speaker knows that Daddy is indeed in Berlin now) and, accordingly, cannot be regarded as a euphemism (Moskvin, 2010:105). Consider the opposite situation: The speaker of Daddy's in Heaven does not believe in life after death. S/he knows that, in reality, Daddy is not in heaven, but is dead and buried in the ground. However, in order not to shock the dead Daddy's small child who wants to know where his/her father now is, the speaker does not tell the truth, Daddy's dead, but instead says Daddy's in Heaven. In this case, the utterance in question is also not a euphemism but a lie, just like the utterance Daddy's in Berlin now uttered when the speaker knows that Daddy is now not in Berlin but instead in, e. g., Kabul.

According to Moskvin (2010:93-94), euphemism is different from lie in that in the former case, the speaker does not intend to deceive or mislead the hearer. That is, for example, when a speaker of English utters a euphemistic utterance like John sleeps with Sarah and John is Sarah's boyfriend, s/he does not want to disguise 
the facts that John and Sarah do not merely sleep together in the same bed and that John is more than just a friend who is a boy. Instead, the speaker wants to communicate the taboo-marked meanings "John copulates with Sarah" and "John is Sarah's regular sexual partner to whom she is not officially married" without explicitly referring to the taboo subject SEx. Hence, a death-related utterance like Daddy's in Heaven can be regarded as a euphemism only in one case: When the speaker wants to indirectly communicate the taboo-marked meaning "Daddy is dead," but not when the speaker wants to conceal the fact of Daddy's death from the hearer. While the former is a euphemism, the latter is a lie. (We will return to this distinction in the final section of this article.)

\section{Euphemism-formation mechanisms: a general classification}

Having specified the definition of euphemism, we can now proceed to euphemismformation mechanisms, i. e., the question of how euphemistic expressions like to sleep with somebody, boyfriend, to be in Heaven, gone from us, etc. come into existence. This issue has been extensively dealt with in a number of studies. For example, Moskvin (2010:163-227, 2001:64-67) discusses how euphemisms are formed in present-day Russian. Reutner (2009:119-154) addresses the same question with respect to French and Italian. Farghal (1995) deals with euphemismformation mechanisms in Arabic. Adams (1981) is concerned with the formation of sexual euphemisms in Latin. As far as the English language is concerned, this question has been dwelled upon by Warren (1992) and, more recently, by LinfootHam (2005), Crespo Fernández (2008, 2007, 2006a, 2006b), and Halmari (2011). (The latter article is concerned with one particular instance of euphemization: a recent replacement of premodified nouns like disabled people by postmodified nouns like people with disabilities.)

Traditionally, euphemism-formation mechanisms have been classified into semantic and non-semantic types (e. g., Warren, 1992:134). An instance of the latter is the famous infixed form with an expletive meaning absoschmuckinglutely (which, according to Adams (1999), can be better described as a euphemistic dysphemism). The euphemistic effect is achieved here by means of a consonant change in the original expletive infix -fucking-: [f] is replaced by the cluster [Sm], as a result of which absoschmuckinglutely can express the same expletive 
meaning as absofuckinglutely, without, however, evoking the negative connotations inherent in -fucking-. Also, instead of changing [f] to [ $\mathrm{fm}]$, fuck can be abbreviated to $f$ - e. g., I'm sorry I said the f-word (Davies, 2008-).

Apart from consonant interchange, abbreviation, and other phonetic modifications, non-semantic strategies are sometimes said to include borrowing (e.g., Moskvin, 2001:67). However, as will be shown below, a loanword often functions as a euphemism not only because it is a loanword, but also because its source language literal meaning is not identical with the taboo-marked meaning that it expresses in the language of a borrowing community. For instance, a doctoral thesis defended at a German university can be graded with the Latin expression cum laude, which literally means "with praise" (Brockhaus, 2005-2006). However, despite its literal meaning in Latin, cum laude is a rather poor dissertation grade in Germany. Thus, a person whose doctoral degree was awarded cum laude is not eligible for most post-doctoral stipends or fellowships, and his thesis will most likely not be accepted for publication by a serious academic press (see, e. g., "Forschungsstipendien für promovierte Nachwuchswissenschaftler (Postdoc-Programm)," n.d.). Accordingly, the euphemistic use of cum laude is possible not only because of the non-German origin of the phrase under consideration (i.e., the fact that the majority of German speakers do not know what cum laude means in Latin), but also because of its literal meaning in Latin ("with praise"), which is a converse of what it actually stands for in German ("poor dissertation"). (The latter fact allows the grader to maximize praise $\mathrm{e}^{2}$ of his doctoral student who presented a poorly written dissertation.) A somewhat similar example is the French borrowing à outrance (literally "to the utmost"), which, in English, is sometimes used as a euphemism for extramarital copulation - e.g., I think if anyone read carefully they would say it was an affair à outrance (Holder, 2008:75). Again, as in the case of cum laude in German, it can be argued that à outrance functions as a euphemism in English not only because it was borrowed from French but also because its French literal meaning of "to the utmost" is not identical with the euphemistic sense "extramarital copulation." (As a matter of fact, à outrance can be used in English not only as a euphemism for "extramarital copulation" but also as a non-euphemistic adverb meaning "to the limit" (Merriam-Webster Online), i. e., what à outrance means in French.)

\footnotetext{
${ }^{2}$ In the sense of the maxim of praise of the Leechian politeness principle (see, e. g., Cruse, 2004:37).
} 
As for purely semantic means, euphemistic expressions can be classified into instances of metonymic and metaphoric semantic change. Following Lakoff and Turner (1989:103), the difference between metonymy and metaphor can be described as within-domain mapping (metonymy) versus cross-domain mapping (metaphor). A conceptual domain is "a more generalized 'background' knowledge configuration against which conceptualization is achieved" (Taylor, 2002:195). For example, in order to understand the meaning of cum laude in German, we need the concept of dissertation grades in German universities, of which the concept of cum laude is a part. Accordingly, we can claim that the former is the domain against which the latter is conceptualized in German.

Like other metonymic expressions, metonymic euphemisms can be classified into whole-for-part, part-for-whole, and part-for-part metonymies. A part-forpart metonymy is a metonymy like cum laude, whose vehicle concept (i. e., its literal meaning) stands for another element within the same conceptual domain. Thus, both the literal meaning "with praise" and the euphemistic sense "poor quality" can be regarded as evaluative characteristics of a doctoral dissertation: i. e., a grader can come to the conclusion that a $\mathrm{Ph} . \mathrm{D}$. thesis either deserves praise or is of poor quality. However, when the latter is the case, the thesis is graded cum laude, even though the grader knows that the thesis is of poor quality and thus does not deserve to be praised. (When the grader comes to the conclusion that the thesis is of good quality and hence deserves praise, s/he grades it with either magna cum laude or summa cum laude, but never with cum laude.) Accordingly, the euphemistic use of cum laude as a dissertation grade in Germany is an instance of part-for-part metonymy: one element of the domain EVALUATIVE CHARACTERISTICS OF A DOCTORAL THESIS ("with praise") stands for another element of the same domain ("poor quality").

A part-for-whole metonymy is a metonymy like boyfriend, whose vehicle concept stands for an entire conceptual domain of which it is a part: As stated in the beginning of the article, boyfriends are often perceived by their girlfriends as friends in the literal meaning of this word (i.e., as any persons whom they know well and regard with affection and trust). Accordingly, the literal concept of friendship can be said to constitute part of the concept of boyfriend-ship, i. e., a boyfriend is not only a sexual partner in a non-marital sexual relationship but also a friend. 
Finally, a whole-for-part metonymy is a metonymy like adult for "erotic / pornographic" - e.g., in the phrase an adult Web site - whose euphemistic sense "erotic / pornographic" is an instance (or a part) of the vehicle concept "adult." The adjective adult literally means "fully developed and mature" (Merriam-Webster Online). Accordingly, the phrase an adult Web site could have meant "any Web site suitable for fully developed and mature people." However, an adult Web site is a particular instance of a Web site appropriate for adults: a Web site that contains pornographic material.

Metaphoric euphemisms fall into those that realize conceptual metaphors and those that are based on one-shot or image metaphors. Conceptual metaphors are characterized by systematic correspondences between their source and target domains (e. g., Lakoff \& Johnson, 1980:52-55). This means that more than one expression pertaining to one and the same source domain can be used in connection with one and the same target domain. For example, the collocation to come to an orgasm (as well as its elliptic version to come) realizes the conceptual metaphor pURPOSES ARE DESTINATIONs (cf. Crespo Fernández, 2008:101): Apart from an orgasm, we also come to a conclusion, a solution, a decision, a verdict, a result, etc. Also, in addition to coming, an orgasm can be reached (e. g., "Are you having trouble reaching orgasm? A guide for women," 2011, May 22) and arrived at (e.g., A very distinctive feature with the female orgasm is that women find it quite hard to arrive at an orgasm from intercourse alone, "How to Make Your Woman Reach an Orgasm Fast!”, 2012, February 29). By contrast, one-shot metaphors involve less systematic correspondences between their source and target domains and are, therefore, perceived as more metaphoric and figurative than conceptual metaphors (Tokar, 2009:8-10). For example, to ride meaning "to copulate with a man in the woman-on-top position" seems to have a much higher degree of metaphoricity than to come meaning "to achieve an orgasm." This is because apart from the visual similarity between a person sitting on a horse / bicycle while riding it and a woman sitting on her sexual partner while copulating with him, no other element of the source domain RIDING A HORSE / BICYCLE takes part in the mapping onto the target domain COPULATING IN THE WOMAN-ON-TOP POSITION. Thus, a male sexual partner whom a woman rides is neither a horse nor a bicycle. We are justified in claiming this because neither to ride a horse nor to ride a bicycle occurs in the sense "to copulate with a man while being on top." 
Since metonymic mappings involve no more than one conceptual domain while metaphoric mappings are cross-domain mappings, metonymic euphemisms can usually be relatively easily distinguished from metaphoric euphemisms: In the former case, we feel that there is a more or less real link between what the expression under analysis literally means and what it denotes as a euphemism. For example, there is a real link between the meanings "with praise" and "poor quality": Both are evaluative characteristics that can be given to a doctoral thesis. Similarly, there is a real link between the meanings "a friend" and "a sexual partner": Sexual partners are often perceived as friends. Finally, there is a real link between the meanings "adult" and "pornographic": Pornography is believed to be harmful to children and is, therefore, appropriate for adults only. By contrast, in the case of a metaphoric euphemism, no such link can be established. Thus, there is no real link between the meanings "to come" and "to achieve an orgasm": Because copulation typically does not involve motion (i.e., lovers do not move from one place to another while having sex), reaching an orgasm cannot be an instance of coming. Similarly, there is no real link between the meanings "to ride" and "to copulate with a man while being on top of him": Since a male lover whom a woman copulates with while being on top is neither a horse nor a bicycle, sexual riding cannot be an instance of physical riding.

In addition to metonymic and metaphoric euphemisms, Warren (1992:131132) classifies semantically motivated euphemisms into instances of the following mechanisms:

- particularization; e.g., satisfaction for "orgasm." This euphemistic meaning of "orgasm" represents a subcategory of the literal meaning "satisfaction": an orgasm is a kind of satisfaction.

- implication; e. g., to go to the toilet for "to urinate and / or defecate." There is an antecedent-consequent relationship between the literal meaning of "to go to the toilet" and the euphemistic meaning of "to urinate / defecate": First of all, we physically move to the place TOILET, and only then do we urinate and / or defecate in it.

- reversal or irony; e.g., enviable disease for "syphilis." The euphemistic use of this expression creates an ironic effect, since syphilis is, of course, not an enviable disease. 
- $\quad$ understatement or litotes; e. g., drug habit for "drug addiction." The undesirable feature DRUG ADDICTION is downgraded to DRUG HABIT, which can be any habit concerning drugs.

- $\quad$ overstatement or hyperbole; e. g., sanitary engineer for "garbage collector." The non-prestigious occupation of a garbage collector is upgraded to that of an engineer.

This article argues against this classification. The major problem with Warren's approach is the fact that it distinguishes between particularization, implication, and metonymy-based euphemisms. Let us begin with the category of particularization. As stated above, particularization euphemisms are expressions like satisfaction for "orgasm," whose euphemistic senses represent a subcategory of what they literally mean. To be more precise, there exists a hyponym-hypernym relationship between the former and the latter. For example, the meaning "orgasm" is a hyponym of the meaning "satisfaction," since, as already mentioned, an orgasm is a kind of satisfaction. Similarly, the euphemistic meaning of the pill, as in, for example, she is on the pill, which stands for "she uses contraceptive pills," is a hyponym of the literal meaning of "pill": A contraceptive pill is a kind of pill. In summary, in particularization euphemisms, such as satisfaction and the pill, the euphemistic effect results from the replacement of a taboo-marked hyponym (orgasm, contraceptive pill) by a taboo-free hypernym (satisfaction, the pill), the latter having a very broad meaning that subsumes a number of taboo-free hyponyms - e.g., apart from contraceptive pills, there are headache pills, sleeping pills, vitamin pills, etc.

Following Moskvin (2001:65, 2010:194-195), this euphemism-formation mechanism can perhaps be better referred to as hypernymization, rather than as particularization; regardless of our terminological choice, however, it must be stressed that all euphemisms of this type are metonymies. Indeed, as correctly analyzed by Kövecses (2006:104), just like the previously mentioned example adult for "pornographic," the euphemistic use of the pill represents a whole-for-part metonymy in which the conceptual domain PILL evokes one of its members: the category of contraceptive pills. In the same way, in the case of satisfaction for "orgasm," the conceptual domain SATISFACTION stands for one of its parts: sexual satisfaction / orgasm. 
Now, let us proceed to the category of implication. That the distinction between metonymy-based and implication euphemisms is untenable can be illustrated with the example bathroom for "toilet." According to Warren, bathroom can be analyzed as a metonymic euphemism because of the locative relationship between the senses "a room with a bath" and "toilet": Toilets often contain a bathtub. (Or alternatively, a bathroom is a room that, apart from a bathtub, also often contains a lavatory pan.) At the same time, however, it can be argued that the euphemistic use of bathroom is motivated by the antecedent-consequent relationship between the events of USING A LAVATORY PAN and USING A BATH. That is, before taking a bath, people usually urinate / defecate in a lavatory pan. (The fact that one and the same room often contains both a bathtub and a lavatory pan corroborates the antecedent-consequent motivation of bathroom.)

A very similar example is the utterance Where can I wash my hands? which, as Kövecses \& Radden (1998:72) point out, can stand for "Where is the nearest toilet?" On the one hand, the underlying motivation seems to be of a locative character: Toilets contain washbasins so that toilet visitors can wash their hands. At the same time, however, the euphemistic use of this utterance can be said to be motivated by the antecedent-consequent relationship between the events URINATION / DEFECATION and WASHING HANDS. In the prototypical case, the latter immediately follows the former: People urinate / defecate in a lavatory pan and then wash their hands in a washbasin. (This explains why toilets are places that contain washbasins.)

The fact that one and the same euphemism can be plausibly analyzed as an instance of both implication and metonymy clearly indicates that the distinction between these two categories cannot be sustained. Like particularization euphemisms, euphemisms involving an antecedent-consequent relationship between their literal and euphemistic senses are also metonymies. The only difference is that implication euphemisms - such as to go to the toilet and Where can I wash my hands? - are not whole-for-part, but rather, they are part-for-whole metonymies. That is, for example, the act of (literally) going to some toilet is part of the prototypical scenario of using toilets: In order to urinate / defecate, we, first of all, literally go to the place TOILET. The same can be said about washing hands. This concept is also part of the prototypical scenario of using toilets: After urination / defecation, we typically wash our hands. 
With regard to the categories of litotes / understatement and hyperbole / overstatement, the following must be noted. As analyzed by Warren (1992), using drug habit for "drug addiction" is an instance of litotes because the negative feature DRUG ADDICTION is downgraded to DRUG HABIT (which can be any feature regarding drugs), whereas the use of sanitary engineer acts as an instance of hyperbole because the non-prestigious occupation GARBAGE COLLECTOR is upgraded to ENGINEER. The problem with this analysis is that it confuses semantic euphemism-formation mechanisms (metonymy and metaphor) with pragmatic effects achieved by them (under- and overstatement). What is meant by this is that, similar to satisfaction and the pill, drug habit can also be analyzed as a wholefor-part metonymy in which the conceptual domain DRUG HABIT stands for one of its members: the category of drug addiction. This semantic strategy underlies the euphemistic use of drug habit and results in the pragmatic downgrading of the negative feature DRUG ADDICTION. (This effect arises because drug addiction is perceived as a bad habit. In contrast, in the case of satisfaction and the pill, there is no pragmatic downgrading because neither an orgasm nor a contraceptive pill is perceived as a bad subcategory of the domains SATISFACTION and PILL: An orgasm is not a bad satisfaction, and a contraceptive pill is not a bad pill.) Similarly, in sanitary engineer the underlying semantic strategy is not overstatement but a part-for-part metonymy in which one member of the domain PROFESSION (engineer) stands for another member of the same domain (garbage collector). As in the case of drug addiction, the upgrading effect arises because the occupation of a garbage collector is perceived as less prestigious than that of an engineer.

In stark contrast to Warren (1992) and some more recent studies (Reutner, 2009:119-154; Moskvin, 2010:163-227), which propose even more refined classifications, the present article recognizes only two semantic euphemism-formation mechanisms: either a metonymic or a metaphoric extension of the euphemism's literal meaning. This view is in full accord with present-day diachronic semantics (e. g., Traugott \& Dasher, 2002), which recognizes only two types of semantic change: metonymy and metaphor. On the contrary, authors like Warren and Moskvin, who distinguish between metonymy and particularization / hypernymization, seem to be influenced by the very old logico-rhetorical typology of semantic change, whose origins "go back to Aristotle's analysis of metaphor" (Ullmann, 1967:203). Thus, for Anttila (1972:148) the semantic development of hound ("any dog" in Old English > "a hunting dog of a particular breed" in Mod- 
ern English) is not a whole-for-part metonymy (in which, like in the case of satisfaction and the pill, the name of the conceptual domain has begun to be used as a metonym for one of its members) but an instance of semantic narrowing. Whereas metonymy and metaphor involve a "transfer to another conceptual sphere," narrowing of meaning as exemplified by hound constitutes a "change within the same conceptual sphere," i. e., a change that did not affect the semantic range of the item under consideration: Hound has retained the semantic component $[\mathrm{dog}]$. As stated above, this article rejects the logico-rhetorical approach and regards semantic narrowing as a whole-for-part metonymy. Correspondingly, cases of semantic widening, such as to arrive for "to arrive at sea" in Old English > "to arrive anywhere and by any means of locomotion" in Modern English (Ullmann, 1967:204) are regarded as part-for-whole metonymies.

\section{Default and non-default metonymies}

In their landmark article entitled "Metonymy: Developing a Cognitive Linguistic Point of View," Kövecses \& Radden (1998) raise the question of why some metonymic expressions are hardly recognizable as expressions that do not mean what they literally stand for. For example, Prime Minister of England is an unrecognizable part-for-whole metonymy meaning "Prime Minister of the entire United Kingdom of Great Britain and Northern Ireland (of which England is a part)": England does not have its own Prime Minister. If Prime Minister of England were a recognizable metonymy, its use would most likely give rise to a semantic anomaly (cf. Prime Minister of Wales). Similarly, black coffee seems to be a hardly recognizable part-for-whole metonymy meaning "coffee without added milk or cream" (Mel'čuk, 1995:182): The vehicle meaning "black color" is a characteristic of the intended target meaning "coffee without milk or cream" (i.e., the absence of milk or cream in a cup of coffee usually results in its black color).

According to Kövecses \& Radden (1998), the non-recognizability of metonymies like England for the United Kingdom of Great Britain and Northern IRELAND and BLACK COLOR FOR ABSENCE OF MILK OR CREAM stems from the fact that the choice of their vehicle concepts ENGLAND and BLACK COLOR fulfills at least some of the cognitive principles of relative salience. These include, for example, 
Metonymic Euphemisms from a Cognitive Linguistic Point of View

- HUMAN OVER NON-HUMAN

- CONCRETE OVER ABSTRACT

- INTERACTIONAL OVER NON-INTERACTIONAL

- IMMEDIATE OVER NON-IMMEDIATE

- DOMINANT OVER LESS DOMINANT

- SPECIFIC OVER GENERIC

- Good gestalt OVER POOR GESTALT

- CENTRAL OVER PERIPHERAL

- RELEVANT OVER LESS RELEVANT

- IMPORTANT OVER LESS IMPORTANT

These principles "relate to three general determinants of conceptual organization" (p. 63):

1. human experience; e.g., HUMAN OVER NON-HUMAN, CONCRETE OVER ABSTRACT, etc.

2. perceptual selectivity; e.g., IMMEDIATE OVER NON-IMMEDIATE, DOMINANT OVER LESS DOMINANT, etc.

3. cultural preference; e. g., CENTRAL OVER PERIPHERAL, IMPORTANT OVER LESS IMPORTANT, etc.

What is important here is that "the more of [these] principles apply to a particular metonymic expression, the greater the cognitive motivation. As a result, the metonymy will be regarded as natural or 'default"' (p. 71). Thus, the unrecognizable metonymy Prime Minister of England is a default metonymy because its vehicle concept ENGLAND fulfills the principle DOMINANT OVER LESS DOMINANT (relating to perceptual selectivity): England is the most dominant part of the United Kingdom of Great Britain and Northern Ireland and can, therefore, be easily understood as a metonym for the entire UK. Similarly, the hardly recognizable metonymy black coffee is a default metonymy because its vehicle concept BLACK COLOR fulfills the principle IMMEDIATE OVER NON-IMMEDIATE (also relating to perceptual selectivity): i. e., first of all, we see that a coffee is black, and only then do we conclude that it contains no milk and cream.

Default metonymies like Prime Minister of England and black coffee can be contrasted with non-default metonymies, i. e., metonymic expressions whose vehicles violate one or more of the above-named principles. For example, the euphemism boyfriend can be considered a non-default metonymy because its vehicle concept 
FRIEND violates the principle IMPORTANT OVER LESS IMPORTANT (or, alternatively, the principles RELEVANT OVER LESS RELEVANT Or CENTRAL OVER PERIPHERAL), relating to cultural preference. The most important characteristic of boyfriend-ship is not friendship, but, rather, the sexual / romantic relationship between a woman and her boyfriend. Friendship is, by contrast, a less important and / or less relevant, even peripheral, characteristic. Thus, a woman can have more than one literal friend, but only the one, who, in addition to being her friend, is also her sexual partner qualifies as her boyfriend. Similarly, the euphemism bathroom can be analyzed as a non-default metonymy because its vehicle concept RоOм WIтH A BATH violates the same principles. The defining characteristic of a toilet is that its visitors urinate / defecate in a lavatory pan, not that they wash themselves in a bathtub.

Given what has been said above, a question arises as to whether all metonymic euphemisms can be regarded as non-default metonymies. (This question is left unanswered by Kövecses and Radden because the focus of their article is not on metonymic euphemisms but on all kinds of metonymic expressions and semantic patterns underlying them.) The answer to this question depends on whether the researcher equates default metonymies with unrecognizable metonymies, i. e., if a given metonymic euphemism is not consciously recognized as an expression that underwent metonymic reinterpretation, it can be considered a non-default metonymy. Consider again the copulation euphemism to sleep with somebody. As a first approximation, this euphemism is also analyzable as a non-default metonymy in which the choice of the vehicle concept violates the principle IMPORTANT OVER Less IMPORTANT. Physical sleeping is a peripheral characteristic of the copulation scenario: Far more important than spending time together in the same bed at night or day time while being in the state of sleep is the fact that lovers engage in sexual intercourse. At the same time, however, it is not clear whether English speakers are consciously aware of this euphemism's metonymic nature. Thus, observe the euphemistic use of to sleep with somebody in contexts that do not involve physical sleeping; e. g., sex with a prostitute, after which the customer typically goes away without literally sleeping with her (e. g., I recently learned that my husband has slept with many prostitutes in third world countries, “Reckless Endangerment of Spouse - Legal Recourse?", 2010). If to sleep with somebody were a recognizable metonymy, than this euphemism would most likely occur in sleeping contexts only. That is, it would refer not only to sexual 
intercourse (euphemistic meaning) but also to physical sleeping (literal meaning), in other words, to a prototypical copulation scenario in which the former is immediately followed by the latter. That to sleep with somebody does, however, occur in non-sleeping contexts as well (and, what is more, this use does not give rise to a semantic anomaly) corroborates the suggestion that the euphemistic meaning "to copulate" does not activate the literal meaning "to sleep." In this respect, to sleep with somebody does not seem to be different from the default metonymy Prime Minister of England.

Alternatively, we can discard the recognizability criterion, i. e., regard a metonymic euphemism like to sleep with somebody as non-default if its vehicle concept violates at least some of the above-named principles. However, in this case, we will inevitably run into the problem of mixed metonymies, i. e., metonymic expressions whose vehicle concepts simultaneously fulfill and violate one or the other principle. A good example illustrating this point is to go to the toilet. On the one hand, this euphemism is a non-default metonymy violating the principle IMPORTANT OVER LESS IMPORTANT: The literal act of going to a toilet is undoubtedly a less important aspect of the using-a-toilet scenario than the act of urination / defecation in it. On the other hand, however, to go to the toilet can be considered a default metonymy because it is motivated by the antecedent-consequent relation between its literal and euphemistic meaning and, accordingly, fulfills the principle IMMEDIATE OVER NON-IMMEDIATE: First of all, we physically go to the place TOILET and only then urinate / defecate in it. What is, then, the status of to go to the toilet? Is it a default or a non-default metonymy?

\section{Classifying metonymic euphemisms}

Since it is not entirely clear in which case a metonymic expression qualifies as default, this article does not apply the default-non-default distinction to metonymic euphemisms. What it does instead, however, is classify metonymic euphemisms with respect to the violation of one particular principle, the one which underlies its euphemistic use. Thus, the fact that the vehicle concept of to go to the toilet fulfills the principle IMMEDIATE OVER NON-IMMEDIATE does not really explain why this expression can function as a euphemism for urination / defecation. (This does explain, however, why to go to the toilet can be understood as a metonym for urination / defecation: In order to urinate / defecate, we, first of all, need to literally 
go to some toilet.) What underlies the euphemistic function of to go to the toilet is that the literal act of going to a toilet is a less important and a taboo-free aspect of the using-a-toilet-scenario. Similarly, the literal act of sleeping is a less important and a taboo-free characteristic of the copulation scenario; literal friendship between a woman and her boyfriend is a less important and a taboo-free characteristic of the concept of boyfriend-ship; etc.

\subsection{Euphemisms violating the principle IMPORTANT OVER LESS IMPORTANT}

Metonymic euphemisms belonging to this category are metonymies like the aforementioned examples to sleep with somebody, boyfriend, to go to the toilet, and bathroom. In all of them, the euphemistic effect results from the replacement of a taboo-marked concept by a less important but taboo-free characteristic associated with the same taboo subject.

Below are some other examples of metonymic euphemisms whose vehicle concepts violate the principle IMPORTANT OVER LESS IMPORTANT. All of these examples have been taken from Richard Holder's (2008) Oxford Dictionary of Euphemisms.

As has been mentioned in connection with to sleep with somebody, metonymic euphemisms belonging to this category can be used in contexts that are not compatible with their literal meanings. That is, we can say fohn sleeps with Sarah even if John and Sarah never fall asleep together in the same bed (e. g., McGlone \& Batchelor, 2003:251). Similarly, as Holder (2008:90) points out, the euphemistic query Where's the basement? can be "made in a building manifestly devoid of a lower level." The reason for this is obvious: Metonymic euphemisms like to sleep with somebody and basement have vehicle concepts denoting peripheral characteristics of the taboo-marked concepts that they express. That is, lovers do not always fall asleep together after sex, and lavatories are not necessarily located in building basements.

Given these uses of to sleep with somebody and basement, one of the anonymous reviewers of this article raises the question of whether euphemisms like these can still be regarded as metonymic euphemisms. That is, if lovers who have sex do not always literally sleep with each other in the same bed, can we still claim that in the case of to sleep with somebody, there exists a real link between the literal 
Table 1: Metonymic euphemisms violating the principle SPECIFIC OVER GENERIC

\begin{tabular}{|c|c|c|c|}
\hline & Euphemism & $\begin{array}{l}\text { Euphemistic } \\
\text { meaning }\end{array}$ & Violation of the principle \\
\hline 1 & African-American & "black" & $\begin{array}{l}\text { Much more important than being a person } \\
\text { whose ancestors came from Africa is the } \\
\text { fact that an African-American is a person } \\
\text { who has a black skin. }\end{array}$ \\
\hline 2 & basement & "lavatory" & $\begin{array}{l}\text { The fact that a lavatory is frequently lo- } \\
\text { cated in the basement of a shopping mall, } \\
\text { school, etc. is a rather peripheral charac- } \\
\text { teristic of the concept LAVATORY. }\end{array}$ \\
\hline 3 & evacuee & $\begin{array}{l}\text { "a German citizen } \\
\text { (usually a Jew) } \\
\text { killed by the } \\
\text { Nazis" }\end{array}$ & $\begin{array}{l}\text { Much more important than being literally } \\
\text { evacuated (i.e., removed from a military } \\
\text { zone or a dangerous place) is the fact that } \\
\text { evacuees were actually killed. }\end{array}$ \\
\hline 4 & $\begin{array}{l}\text { disturbed, as in, } \\
\text { e.g., disturbed } \\
\text { child }\end{array}$ & "naughty" & $\begin{array}{l}\text { Much more important than being literally } \\
\text { disturbed by somebody or something is the } \\
\text { fact that a disturbed child is naughty, i. e., } \\
\text { that he or she does not behave well. }\end{array}$ \\
\hline 5 & $\begin{array}{l}\text { massage parlor / } \\
\text { sauna }\end{array}$ & "brothel" & $\begin{array}{l}\text { Much more important than being a place } \\
\text { where customers can get a massage / wash } \\
\text { themselves in a sauna is the fact that both a } \\
\text { massage parlor and a sauna are places for } \\
\text { paid sex. }\end{array}$ \\
\hline 6 & mature & "old" & $\begin{array}{l}\text { Much more important than being literally } \\
\text { mature (i. e., fully developed) is the fact } \\
\text { that a mature person is relatively old. }\end{array}$ \\
\hline 7 & $\begin{array}{l}\text { non-industrial } \\
\text { country }\end{array}$ & $\begin{array}{l}\text { "poor and } \\
\text { relatively } \\
\text { uncivilized } \\
\text { country" }\end{array}$ & $\begin{array}{l}\text { Much more important than the absence } \\
\text { of industry is the fact that a non-industrial } \\
\text { country is a poor country. }\end{array}$ \\
\hline 8 & oldest profession & "prostitution" & $\begin{array}{l}\text { Being the oldest profession is a peripheral } \\
\text { characteristic of the concept PROSTITUTION. }\end{array}$ \\
\hline 9 & $\begin{array}{l}\text { red lamp / red } \\
\text { light, as in, e. g., } \\
\text { red light district }\end{array}$ & "brothel" & $\begin{array}{l}\text { Even though many brothels use red lamps } \\
\text { as their sign, this is, nevertheless, a periph- } \\
\text { eral characteristic of the concept BROTHEL. }\end{array}$ \\
\hline 10 & visible & $\begin{array}{l}\text { "not } \\
\text { white-skinned" }\end{array}$ & $\begin{array}{l}\text { Much more important than being literally } \\
\text { visible is the fact that a visible person does } \\
\text { not have a white skin. }\end{array}$ \\
\hline
\end{tabular}

meaning "to sleep" and the euphemistic meaning "to copulate"? According to the reviewer, it can also be argued that "the two activities (sleeping with someone and having sex with someone) share the aspect of privacy / intimacy, so that one may be used as a metaphoric expression for the other." 
In my view, the proposed analysis of to sleep with somebody as a metaphoric euphemism is not correct. Despite the fact that sex is not always followed by lovers' co-sleeping, the expression to sleep with somebody still remains a metonymically motivated euphemism. That is, when asked "Why can to sleep with somebody be used as a euphemism for 'to have sex'?", a speaker of English, who uses this expression in both sleeping and non-sleeping contexts, will still attribute the idiomatic meaning "to have sex" to the antecedent-consequent relationship between the events of HAVING SEX and SLEEPING: The latter is often immediately followed by the former.

It is true that the activities of having sex and sleeping with someone share the aspect of privacy / intimacy. However, this does not mean that to sleep with somebody can be analyzed as a metaphoric euphemism. Quite the contrary - this fact corroborates the metonymic analysis advocated in this article: We can claim that to sleep with somebody is a part-for-part metonymy in which one element of the domain PRIVACY / INTIMACY - the concept of sleeping with someone - maps onto another element within the same domain: the concept of having sex.

\subsection{Euphemisms violating the principle SPECIFIC OVER GENERIC}

Another euphemism-formation strategy involving metonymy is the violation of the principle SPECIFIC OVER GENERIC (which, according to Kövecses \& Radden (1998:67-68), relates not to cultural preferences, but to perceptual selectivity). This strategy underlies all whole-for-part metonymies like the previously mentioned adult Web site for "pornographic Web site," satisfaction for "orgasm," and the pill for "contraceptive pill," which Warren (1992) and Moskvin (2001, 2010) analyze as instances of particularization / hypernymization. Euphemisms belonging to this category violate the principle SPECIFIC OVER GENERIC because they express rather specific concepts like PORNOGRAPHIC WEB SITE, ORGASM, and CONTRACEPTIVE PILL by means of rather generic concepts like ADULT WEB SITE, SATISFACTION, and THE PILL. Usually, the latter represents a hypernym of the former, but observe the euphemistic use of do it in sentences like They did it, meaning "they had sex with each other." It is clear that do it cannot be a hypernym of copulate because it is a deictic pronoun, which has no literal meaning of its own. As argued by Moskvin (2010:197-201), in the case of euphemistic utterances like They did it, we are dealing with pronominalization, another important euphemism- 
formation mechanism, which must be distinguished from hypernymization. In my view, however, this distinction is superfluous. In both pronominalization and hypernymization euphemisms, the euphemistic effect results from the violation of one and the same principle: SPECIFIC OVER GENERIC: As in the case of adult Web site, satisfaction, and the pill, DO IT represents a vehicle that has a very generic meaning, i.e., apart from the taboo-marked target concept COPULATION, it can refer to almost any activity.

Table 2 provides some further examples of euphemistic expression whose vehicle concepts violate the principle SPECIFIC OVER GENERIC. All of these examples have been taken from Holder (2008).

\subsection{Euphemisms violating the principle MORE TRUE OVER LESS TRUE}

Finally, there are metonymic euphemisms like the previously mentioned cum laude for "a bad dissertation grade defended in a German university" and sanitary engineer for "garbage collector," whose vehicle concepts provide rather inaccurate characteristics of what these expressions denote as euphemisms. Thus, as argued in the previous section, a dissertation awarded cum laude is, in reality, a rather poor dissertation that does not deserve any praise. Similarly, the profession of a garbage collector is considerably different from that of an engineer. (Kövecses \& Radden (1998) do not mention the principle MORE TRUE OVER LESS TRUE in their article, but I believe that it is precisely the violation of this principle that accounts for the euphemistic use of all metonymic expressions discussed in this section of the article).

Euphemisms whose vehicle concepts violate the principle MORE TRUE OVER LESS TRUE can often be found among names of various insurances. For example, a health insurance, which covers medical expenses when the insured falls ill, can be better described as an illness (rather than as health) insurance: We need this insurance mainly when we are ill, not when we are healthy. Similarly, a life insurance, which "guarantees a specific sum of money to a designated beneficiary upon the death of the insured" (American Heritage Dictionary), can be better referred to as a death (rather than as life) insurance. According to Holder (2008:211), in the case of health insurance and life insurance, the taboo subjects ILLNESSES and DEATH are avoided by talking about their converses: HEALTH and LIFE. 
Table 2: Metonymic euphemisms violating the principle IMPORTANT OVER LESS IMPORTANT

\begin{tabular}{|c|c|c|c|}
\hline & Euphemism & $\begin{array}{l}\text { Euphemistic } \\
\text { meaning }\end{array}$ & Violation of the principle \\
\hline 1 & abnormal & "homosexual" & $\begin{array}{l}\text { One can be perceived as abnormal in a variety } \\
\text { of ways, not only by being homosexual. }\end{array}$ \\
\hline 2 & $\begin{array}{l}\text { to adjust your } \\
\text { dress }\end{array}$ & $\begin{array}{l}\text { "to do up the } \\
\text { fasteners on your } \\
\text { trousers" }\end{array}$ & $\begin{array}{l}\text { One can adjust his dress in a variety of ways, } \\
\text { not necessarily by doing up the fasteners on his } \\
\text { trousers. }\end{array}$ \\
\hline 3 & $\begin{array}{l}\text { to betray / to } \\
\text { deceive }\end{array}$ & $\begin{array}{l}\text { "to copulate with } \\
\text { a third party } \\
\text { while married" }\end{array}$ & $\begin{array}{l}\text { One can betray / deceive in a variety of ways, } \\
\text { not only by copulating with a third party while } \\
\text { being married / having a regular sexual partner. }\end{array}$ \\
\hline 4 & career change & $\begin{array}{l}\text { "dismissal from } \\
\text { employment" }\end{array}$ & $\begin{array}{l}\text { Our careers can change in a variety of ways, } \\
\text { not necessarily through dismissal from employ- } \\
\text { ment. }\end{array}$ \\
\hline 5 & to cleanse & $\begin{array}{l}\text { "to free from } \\
\text { enemy } \\
\text { occupation or } \\
\text { sympathizers" }\end{array}$ & $\begin{array}{l}\text { One can cleanse in a variety of ways, not only } \\
\text { by freeing from enemy occupation or sympa- } \\
\text { thizers. }\end{array}$ \\
\hline 6 & $\begin{array}{l}\text { to do the right } \\
\text { thing }\end{array}$ & $\begin{array}{l}\text { "to marry a } \\
\text { woman you have } \\
\text { impregnated" }\end{array}$ & $\begin{array}{l}\text { One can do a right thing in a variety of ways, } \\
\text { not only by marrying an impregnated woman. }\end{array}$ \\
\hline 7 & to downsize & $\begin{array}{l}\text { "to dismiss } \\
\text { employees" }\end{array}$ & $\begin{array}{l}\text { One can downsize in a variety of ways, not } \\
\text { only by dismissing employees. }\end{array}$ \\
\hline 8 & erection & $\begin{array}{l}\text { "an enlargement } \\
\text { of the penis due } \\
\text { to sexual } \\
\text { excitement" }\end{array}$ & $\begin{array}{l}\text { Erection literally means "the condition of being } \\
\text { upright" (Holder:169). There are many things } \\
\text { that can be in that condition, not only the penis } \\
\text { of a sexually excited male. }\end{array}$ \\
\hline 9 & $\begin{array}{l}\text { financial } \\
\text { assistance }\end{array}$ & $\begin{array}{l}\text { "state aid for the } \\
\text { poor" }\end{array}$ & $\begin{array}{l}\text { State aid for the poor is not the only kind of } \\
\text { financial assistance. }\end{array}$ \\
\hline 10 & good time & $\begin{array}{l}\text { "a sexual } \\
\text { experience with } \\
\text { a stranger" }\end{array}$ & $\begin{array}{l}\text { One can have a good time in a variety of ways, } \\
\text { not only by having a sexual experience with a } \\
\text { stranger. }\end{array}$ \\
\hline
\end{tabular}

Some other examples of metonymic euphemisms belonging to this category are given in Table 3.

Metonymic euphemisms of this type are often hardly distinguishable from metaphoric euphemisms (and can perhaps be regarded as a borderline case between metonymy and metaphor). Like the former, the latter can also be analyzed as violations of the principle MORE TRUE OVER LESS TRUE. For example, we can say that the vehicle concepts of the metaphoric expressions to come for "to achieve an orgasm" and to ride for "to copulate with a man in the woman-on-top position" 


\section{Metonymic Euphemisms from a Cognitive Linguistic Point of View}

Table 3: Metonymic euphemisms violating the principle MORE TRUE OVER LESS TRUE

\begin{tabular}{|c|c|c|c|}
\hline & Euphemism & Euphemistic meaning & Violation of the principle \\
\hline 1 & academy & "brothel" & $\begin{array}{l}\text { The institution of an academy is } \\
\text { considerably different from that } \\
\text { of a brothel. }\end{array}$ \\
\hline 2 & actress & "prostitute" & $\begin{array}{l}\text { The profession of an actress is con- } \\
\text { siderably different from that of a } \\
\text { prostitute. }\end{array}$ \\
\hline 3 & $\begin{array}{c}\text { to angle with a silver } \\
\text { hook }\end{array}$ & $\begin{array}{l}\text { "to pretend to have } \\
\text { caught a fish that you } \\
\text { have bought" }\end{array}$ & $\begin{array}{l}\text { A person who behaves in such a } \\
\text { way does not literally angle with } \\
\text { a silver hook. }\end{array}$ \\
\hline 4 & art & "pornographic" & Pornography is not an art. \\
\hline 5 & $\begin{array}{l}\text { as planned (used as } \\
\text { "corporate-speak } \\
\text { when managers wish } \\
\text { to suggest that their } \\
\text { failure is not due to } \\
\text { their incompetence"; } \\
\text { Holder:83) }\end{array}$ & "regrettably" & $\begin{array}{l}\text { Failures like these are not really } \\
\text { planned by managers. }\end{array}$ \\
\hline 6 & aunt & $\begin{array}{l}\text { "a promiscuous woman } \\
\text { or an elderly prostitute" }\end{array}$ & $\begin{array}{l}\text { A promiscuous woman or an el- } \\
\text { derly prostitute is not an aunt in } \\
\text { relation to the person who refers } \\
\text { to her as an aunt. }\end{array}$ \\
\hline 7 & bamboozled & "drunk" & $\begin{array}{l}\text { A drunk person has not literally } \\
\text { been bamboozled, i. e., deceived } \\
\text { by underhanded methods (Merri- } \\
\text { am-Webster Online) }\end{array}$ \\
\hline 8 & beaver $^{3}$ & $\begin{array}{l}\text { "the female genitals } \\
\text { viewed sexually" ("from } \\
\text { the slang meaning a } \\
\text { beard, whence the pubic } \\
\text { hair"; Holder:92 ) }\end{array}$ & The pubic hair is not a beard. \\
\hline 9 & bikini wax & $\begin{array}{l}\text { "a procedure for the } \\
\text { removal of women's } \\
\text { pubic hair" }\end{array}$ & $\begin{array}{l}\text { It is the skin of a woman's body } \\
\text { that is waxed, not the bikini. }\end{array}$ \\
\hline 10 & bimbo & $\begin{array}{l}\text { "a sexually complaisant } \\
\text { female" ("from the } \\
\text { Italian, meaning 'little } \\
\text { (male) child"'; } \\
\text { Holder:95) }\end{array}$ & $\begin{array}{l}\text { A sexually complaisant female is } \\
\text { not a little male child. }\end{array}$ \\
\hline
\end{tabular}

${ }^{3}$ Like to bang somebody, beaver is in present-day English a dysphemism (i. e., a rather vulgar expression for "the female genitalia viewed sexually"), rather than a euphemism. It is not entirely clear why Holder (2008) analyzes it as a euphemism. 
provide very inaccurate descriptions of what happens when people come to an orgasm and copulate while being on top. The reason why to come and to ride can, nevertheless, be better analyzed as instances of metaphor, while the examples in Table 3 are products of a metonymic semantic change, is that in contrast to the former, the latter fulfill the aforementioned within-domain-mapping requirement of metonymy. Consider, for example, the noun beaver for "the female genitals viewed sexually." At first glance, there does not seem to exist a real link between the meanings "beaver" and "the female genitals": Beavers do not seem to have much in common with the female genitalia viewed sexually. However, as Holder argues, the sexual sense of beaver goes back not to the literal meaning "beaver," but to the slang meaning "a beard" (which is a product of metaphorization of the literal meaning "beaver": There is a visual similarity between a beaver and a beard). In this case, beaver can be analyzed a part-for-part metonymy whose vehicle concept BEARD maps onto the target concept THE FEMALE GENITALIA within the same domain HUMAN BODY. Similarly, we can analyze bimbo as a part-for-part metonymy, rather than as a cross-domain metaphor, because its literal meaning in Italian, "a little male child," and its euphemistic sense in English, "a sexually complaisant female," are both human characteristics: i. e., a human being can be a little male child and a sexually complaisant woman. Accordingly, bimbo is a part-for-part metonymy whose vehicle concept LITTLE MALE CHILD maps onto the target concept SEXUALLY COMPLAISANT WOMAN within the same domain of HUMAN CHARACTERISTICS.

In addition to metaphoric euphemisms, metonymic euphemisms whose vehicle concepts violate the principle MORE TRUE OVER LESS TRUE are also often not easily distinguishable from instances of lying. Consider, for example, the famous abbreviation GDR for "German Democratic Republic." Like the examples discussed above, $G D R$ is a part-for-part metonymy in which one element of the conceptual domain POLITICAL SYSTEMS - democracy - stands for another element within the same domain: totalitarianism. Since democracy is radically different from totalitarianism and GDR was indeed a totalitarian state rather than a democracy, it can be concluded that, in this abbreviation, the choice of the vehicle concept DEMOCRATIC violates the principle MORE TRUE OVER LESS TRUE. (This is presumably the reason for the inclusion of GDR in Holder's dictionary of euphemisms.) However, recall that euphemism is different from lie in that, in the former case, the speaker does not intend to deceive or mislead the hearer. That is, a German 
professor who grades a doctoral dissertation with cum laude does not want to be understood literally (i.e., that he indeed thinks that the dissertation he has graded deserves praise). On the contrary, by using the grade cum laude, s/he wants to indirectly communicate the meaning "this is a rather poor dissertation that cannot be praised." By contrast, the coiners of the abbreviation GDR (as well as GDR rulers) wanted to be understood literally (i. e., that GDR was a genuinely democratic country and not a totalitarian state). The use of German Democratic Republic as the official name of the East German State was, thus, a lie because the leaders of the country knew that GDR was not a democracy but nevertheless used this abbreviation for political propaganda.

\subsection{Mixed types}

A number of metonymic euphemisms have vehicle concepts that simultaneously violate the principles IMPORTANT OVER LESS IMPORTANT and MORE TRUE OVER LESS TRUE. A good example is industrializing country for "a poor and relatively undeveloped country." On the one hand, its vehicle concept clearly violates the principle IMPORTANT OVER LESS IMPORTANT: The most important characteristic of an industrializing country is its poverty and underdevelopment, not that it has an ongoing industrialization, as the adjective industrializing suggests. In addition to this, however, there is also a violation of the principle MORE TRUE OVER LESS TRUE: As Holder (2008:226) points out, industrializing country is a "coinage based on aspiration rather than reality." What is meant by this is that an industrializing country is typically a poor and underdeveloped country that has very little or no industry at all. (There is no ongoing industrialization.) Similarly, the educational euphemism differently-abled for "crippled or of low intelligence" violates both the principles IMPORTANT OVER LESS IMPORTANT and MORE TRUE OVER LESS TRUE. With regard to the former, the defining characteristic of a differently-abled person is his crippleness or low intelligence, not the presence of other abilities. With regard to the latter, differently-abled, like industrializing country, also seems to be a coinage based on aspiration rather than reality: A differently-abled person does not really have any different abilities. Finally, recall that to sleep with somebody and basement can be used to refer to lovers who do not fall asleep together in the same bed after having sex and to lavatories that are not located in building basements. Given these facts, we can claim that the vehicle concepts of the 
euphemisms to sleep with somebody and basement simultaneously violate the principles IMPORTANT OVER LESS IMPORTANT and MORE TRUE OVER LESS TRUE: Physical sleeping with somebody is a peripheral characteristic of the prototypical copulation scenario, which, in a number of cases (e. g., during sex with prostitutes), does not immediately follow the more important characteristic SEXUAL INTERCOURSE. Additionally, the fact that lavatories are often located in building basements is a peripheral characteristic of a lavatory that is not true of all lavatories. (As the examples to sleep with somebody and basement demonstrate, euphemisms whose vehicle concepts violate the principle IMPORTANT OVER LESS IMPORTANT are particularly prone to develop into euphemisms violating the principle MORE TRUE OVER LESS TRUE.)

\section{Concluding remarks}

The central claim of this article is that there exists a relatively small number of metonymy-based euphemism-formation mechanisms. One is to express a taboomarked target by means of a less important but taboo-free vehicle associated with the target (violation of the principle IMPORTANT OVER LESS IMPORTANT). In addition, a euphemism can be created by means of replacing a taboo-marked target by either a very generic taboo-free vehicle (violation of the principle SPECIFIC OVER GENERIC) or by a not entirely accurate or even untrue taboo-free vehicle (violation of the principle MORE TRUE OVER LESS TRUE). The major advantage of this classification is that it provides an explanation for why a particular euphemistic expression can function as a euphemism, i. e., be used for indirectly expressing taboo-marked concepts. For example, boyfriend can function as a euphemism for "a male sexual partner in a non-marital sexual relationship" because its vehicle concept FRIENDSHIP provides a peripheral characteristic of the target concept BOYFRIEND-SHIP; adult Web site can function as a euphemism for "a pornographic Web site" because its vehicle concept ADULT WeB site provides a very generic description of what an adult Web site is. Furthermore, health insurance can function as a euphemism for "illness insurance" because its vehicle concept HEALTH INSURANCE provides a rather inaccurate description of why we need a health insurance. Another major advantage is that this classification demonstrates a connection between metonymy- and metaphor-based euphemism-formation mechanisms. As we have seen, metaphoric euphemisms like to come and to ride also violate the 


\section{References}

principle MORE TRUE OVER LESS TRUE and are, therefore, sometimes not easily distinguishable from metonymies like health insurance, sanitary engineer, beaver, and the like.

\section{Acknowledgements}

I would like to thank two anonymous reviewers for their extremely helpful comments on an earlier version of this article. Special thanks go to my former colleague Wiebke Ostermann for her scrupulous proofreading of the final version of the manuscript. I, alone, am responsible for any remaining errors and shortcomings.

\section{References}

Adams, J. 1981. A type of sexual euphemism in Latin. Phoenix, 35 (2). 120-128.

Adams, M. 1999. Another effing euphemism. American Speech, 74 (1). 110-112.

Adult. 2013. Merriam-Webster Online. Retrieved March 29, 2014 from http://www .merriam-webster.com/dictionary/adult

Anttila, R. 1972. An introduction to historical and comparative linguistics. New York: The MacMillan Company.

À outrance. 2014. Merriam-Webster Online. Retrieved March 29, 2014 from http:// www.merriam-webster.com/dictionary/à+outrance

Are you having trouble reaching orgasm? A guide for women. (2011, May 22). Retrieved March 29, 2014 from http://tinyurl.com/cjq35ce

Bamboozle. 2014. Merriam-Webster Online. Retrieved March 29, 2014 from http:// www.merriam-webster.com/dictionary/bamboozled

Bang. 2014. Merriam-Webster Online. Retrieved March 29, 2014 from http://www .merriam-webster.com/dictionary/bang

Blank, A. 1999. Why do new meanings occur? A cognitive typology of the motivations for lexical semantic change. In A. Blank, \& P. Koch (eds.), Historical semantics and cognition, 61-91. Berlin/New York: Mouton de Gruyter.

Crespo Fernández, E. 2006a. Metaphor in the euphemistic manipulation of the taboo of sex. Babel: Aspectos de Filoloxía Inglesa e Alemá, 15, 27-42.

Crespo Fernández, E. 2006b. The language of death: Euphemism and conceptual metaphorization in Victorian obituaries. SKY fournal of Linguistics 19. 101- 
130.

Crespo Fernández, E. 2007. El eufemismo y el disfemismo: Procesos de manipulación del tabú en el lenguaje literario ingles. Alicante: University of Alicante Press.

Crespo Fernández, E. 2008. Sex-related euphemism and dysphemism: An analysis in terms of Conceptual Metaphor Theory. Fournal of the Spanish Association of Anglo-American Studies 30 (2). 95-110.

Cruse, A. 2004. Meaning in language: An introduction to semantics and pragmatics (2nd ed.). Oxford: Oxford University Press.

Cum laude. 2005-2007. In Brockhaus - die Enzyklopädie in 30 Bänden (21st fully revised ed.). Mannheim: F. A. Brockhaus.

Davies, M. 2008-. The corpus of contemporary American English (COCA). Retrieved March 29, 2014 from http://corpus.byu.edu/coca/

Farghal, M. 1995. Euphemism in Arabic: A Gricean interpretation. Anthropological Linguistics 37 (3). 366-378.

Forschungsstipendien für promovierte Nachwuchswissenschaftler (Postdoc-Programm). (n. d.). Deutscher Akademischer Austausch Dienst. Retrieved March 29, 2014 from http://tinyurl.com/cdkgtan

Friend. 2014. WordNet: A lexical database for English. Princeton: Cognitive Science Laboratory of Princeton University. Retrieved March 29, 2014 from http:// wordnetweb.princeton.edu/perl/webwn?s=friend\&sub=Search+WordNet\&o2 $=\& 00=1 \& 08=1 \& 01=1 \& 07=\& 05=\& 09=\& 06=\& 03=\& 04=\& \mathrm{~h}=$

Halmari, H. 2011. Political correctness, euphemism, and language change: The case of 'people first.' Journal of Pragmatic 43. 828-840.

Holder, R. W. 2008. Oxford dictionary of euphemisms: How not to say what you mean (4th ed.). Oxford: Oxford University Press.

How to make your woman reach an orgasm fast! 2012, February 29. Retrieved March 29, 2014 from http://www.articletrader.com/society/sexuality/how-to -make-your-woman-reach-an-orgasm-fast.html

Kövecses, Z. 2006. Language, mind, and culture: A practical introduction. Oxford: Oxford University Press.

Kövecses, Z., \& Radden, G. 1998. Metonymy: developing a cognitive linguistic view. Cognitive Linguistics 9 (1). 37-77.

Lakoff, G., \& Johnson, M. 1980. Metaphors we live by. Chicago: The University of Chicago Press. 


\section{References}

Lakoff, G., \& Turner, M. 1989. More than cool reason: A field guide to poetic metaphor. Chicago: The University of Chicago Press.

Life insurance. Fourth Edition 2000. Updated in 2009. The American Heritage Dictionary of the English Language. Published by Houghton Mifflin Company. Retrieved March 29, 2014 from http://www.thefreedictionary.com/Life -insurance

Linfoot-Ham, K. 2005. The linguistics of euphemism: A diachronic study of euphemism formation. fournal of Language and Linguistics 4 (2). 227-263.

McGlone, M., \& Batchelor, J. 2003. Looking out for number one: Euphemism and face. Fournal of Communication 53 (2). 251-264.

Mel'čuk, I. 1995. Phrasemes in language and phraseology in linguistics. In M. Everaert, E.-J. van der Linden, A. Schenk, \& R. Schreuder (eds.), Idioms: structural and psychological perspectives, 167-223. Hilsdale: Lawrence Erlbaum Associates.

Moskvin, V. P. 2001. Èvfemizmy: Sistemnye svjazi, funkcii i sposoby obrazovanija [Euphemisms: Systemic relations, functions and formation mechanisms]. Voprosy Jazykoznanija 3. 58-70.

Moskvin, V. P. 2010. Èvfemizmy v leksičeskoj sisteme sovremennogo russkogo jazyka [Euphemisms in the lexical system of modern Russian] (4th ed.). Moscow: Lenand.

Pound, L. 1936. American euphemisms for dying, death, and burial: An anthology. American Speech 11 (3). 195-202.

Reutner, U. 2009. Sprache und Tabu: Interpretationen zu Französischen und Italienischen Euphemismen. Tübingen: Max Niemeyer.

Taylor, J. 2002. Cognitive grammar. Oxford: Oxford University Press.

Tokar, A. 2009. Metaphors of the Web 2.0: With special emphasis on social networks and folksonomies. Frankfurt am Main: Peter Lang.

Traugott, E. C., \& Dasher, R. B. 2002. Regularity in semantic change. Cambridge: Cambridge University Press.

Ullmann, S. 1967. The principles of semantics (2nd ed.). Oxford: Basil Blackwell.

Warren, B. 1992. What euphemisms tell us about the interpretation of words. Studia Linguistica 46 (2). 128-172. 


\section{Author}

Alexander Tokar

Department of Linguistics

University of California at Berkeley

alexandertokar1980@gmail.com 